\title{
Do Rating Agencies Confirm or Surprise the Market?
}

\author{
Evelina Lazareva ${ }^{1}$
}

Published online: 12 February 2016

(C) The Author(s) 2016. This article is published with open access at Springerlink.com

\section{JEL $\mathrm{G} 01 \cdot \mathrm{G} 010 \cdot \mathrm{G} 14 \cdot \mathrm{G} 24$}

This paper examines the impact of the Big Three (i.e. Standard \& Poor's, Moody's and Fitch) announcements on sovereign bond indexes. Credit rating agencies (CRAs) have frequently been accused by the press and political leaders for deepening the financial crisis, by surprising the market with rating downgrades and/or negative outlooks of sovereign debts (Boninghausen and Zabel, Journal of International Finance and Money 2015). The idea is that if assessment models used by CRAs employ available information better than the market does, rating announcements provide "new" information (Cavallo et al., http://web.mit.edu/rigobon/www/Robertos_Web_Page/int__credrate. html. 2008). But, CRAs could also use this power to drive the market up or down and many downgrades in the Eurozone were considered "destabilizing" and "excessive," feeding belief in a conspiracy theory. On the other hand, many financial economists believe that the market is relatively efficient and assessment of sovereign debts cannot surprise financial investors. This is due to the absence of asymmetric information between the market and CRAs. Differently from private companies, all the information used in assessing sovereign debts are publicly available and assigned free of charge by at least two major CRAs. Thus efficient markets price this information immediately after news occurs (Hirsch and Bannier, https:/www.ifk-cfs.de/fileadmin/ downloads/publications/wp/08_02.pdf. 2007). It implies that CRAs simply "certify" what the market has priced already and are not able to drive the market as suggested by conspiracy theory.

We employ an event-study methodology to a sample of 43 bond indexes from Bloomberg over the period 1962 to 2013 to test if the market anticipates the news, or if CRAs can shock the financial market with their rating announcements. In particular, we propose four separate hypotheses. The first hypothesis $\left(\mathrm{H}_{1}\right)$ tests for the overall significance of announcements by CRAs. The second hypothesis $\left(\mathrm{H}_{2}\right)$ checks

Evelina Lazareva

evelinalazareva@gmail.com

1 Nottingham Business School, Nottingham Trent University, Nottingham, UK 
separately the impact of negative and positive announcements. To investigate whether the market efficiency hypothesis and/or conspiracy theory holds $\left(\mathrm{H}_{3}\right)$, we split the event windows in two and test the impact of announcements in the pre- and post-event window. Our last hypothesis $\left(\mathrm{H}_{4}\right)$ examines the market efficiency hypothesis and conspiracy theory individually for each CRA.

Our empirical specification consists of a parsimonious capital asset pricing (CAP)like model for bonds derived from the yield curve. We rely on bond indexes as they determine the annual interest rate rolling over bonds continuously when they mature. We calculate the bond index price from yield to maturity and obtain a time series with features similar to equity prices. Then, we compute the daily rate of return on bond index prices, the dependent variable used in our CAP-like model. As there is no market bond index to use as an independent variable, we can build the CAP-like model exploiting the term structure of interest rates. The impact should be similar for positive and negative announcements in the sense that short-term reactions should be more (positively and negatively) intense than long-term ones. Basically, this is a CAP model where we replace equity returns with short-term bond index returns and market returns with long-term bond index returns, hence the term 'CAP-like' model. As risk increases with maturity, we expect a beta lower than one because of the investors' preference for liquidity.

We find that CRAs announcements affect sovereign bond returns. The largest reaction is after a negative announcement, supporting conspiracy theory. Positive announcements are significant before the event, a pattern in line with the market efficiency hypothesis, but their effect is broadly only one-third the size of negative post-event announcements. Fitch and Moody's announcements are coherent with conspiracy theory, whereas the market is able to anticipate rating assessments issued by Standard \& Poor's. We apply different estimators to control for country and day effects because they could produce biased test statistics. Our results are robust to different samples, subperiods, window sizes, specifications and variable definitions. The policy implication of our results is that the regulator/supervisor should reduce the power attributed to ratings in accounting standards, and not assign an excessively influential role to these agencies. This is particularly true for the Eurozone. Its members are negatively affected by rating announcements, whereas important financial markets, such as the United States, United Kingdom, Japan and Switzerland, seem to avoid the negative effects of rating assessments. Our paper contributes to the exiting literature on CRAs in three ways: (i) we develop a parsimonious and simple CAP-like model for bonds, (ii) we develop a structured framework for testing hypotheses on CRAs' announcements, (iii) we provide evidence in favour of conspiracy theory.

Acknowledgments I would like to thank my dissertation supervisor Dr. Francesco Marchionne, Prof. Rob Ackrill and other members of Nottingham Business School for their extreme patience in the face of numerous obstacles.

Open Access This article is distributed under the terms of the Creative Commons Attribution 4.0 International License (http://creativecommons.org/licenses/by/4.0/), which permits unrestricted use, distribution, and reproduction in any medium, provided you give appropriate credit to the original author(s) and the source, provide a link to the Creative Commons license, and indicate if changes were made. 